\title{
Are you sure you can do a perfect Maze?
}

\author{
Leonid Sternik, MD
}

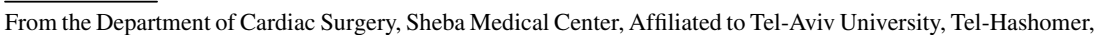
Israel.

Disclosures: Author has nothing to disclose with regard to commercial support.

Received for publication April 26, 2018; revisions received April 26, 2018; accepted for publication April 26, 2018; available ahead of print July 13, 2018.

Address for reprints: Leonid Sternik, MD, Department of Cardiac Surgery, Sheba Medical Center, Tel-Hashomer, Israel (E-mail: Leonid.sternik@sheba.health.gov.il).

J Thorac Cardiovasc Surg 2018;156:1514

$0022-5223 / \$ 36.00$

Copyright (c) 2018 by The American Association for Thoracic Surgery

https://doi.org/10.1016/j.jtcvs.2018.04.124

First of all I thank the authors for this important and excellently written report. ${ }^{1}$ We all know that some patients after mitral valve surgery suffer from new (de novo) atrial fibrillation (AF) in the late follow-up. The authors carefully studied a large group of patients and provided us with numbers: the 5- and 10-year incidence of new AF is $14 \%$ and $23 \%$, respectively. A group from Mayo Clinic reported similar numbers. ${ }^{2}$ We know that AF is a risk factor for stroke, and the authors proved it. Stulak and colleagues reported that de novo AF significantly reduces late survival. ${ }^{2} \mathrm{AF}$ catheter or surgical ablation late after mitral repair or replacement is a challenging procedure with a pretty low success rate. So, we have to do something to prevent de novo AF late after mitral surgery.

The authors reported that the risk factors for de novo AF are older age, comorbidities, coronary artery bypass or coronary disease, aortic and tricuspid valve surgeries, pacemaker implantation, congestive heart failure, and nondegenerative mitral disease. For me, the need for the aortic and especially tricuspid surgery means more advanced disease. The authors concluded that a trial of prophylactic surgical AF ablation, especially in high-risk patients, to limit the development of late $\mathrm{AF}$ might be warranted. I believe that if one is going to do a prophylactic surgical ablation procedure this procedure must be perfect. We cannot afford in this case any atypical flutters, noncontractile atria, or pacemaker implantation.

The authors reported that longer cardiopulmonary bypass and cross-clamp time as well as longer hospital stay are the risk factors for de novo AF. However, the finding that patients who developed in-hospital postoperative AF were more likely to develop late de novo $\mathrm{AF}(P<.001)$ was very interesting to me. We are aware that AF begets $A F$ and aggressive treatment of early postoperative AF can reduce the amount of AF in late follow-up. ${ }^{3}$ Another important finding was that late tricuspid regurgitation was associated with AF. Stulak and colleagues pointed out that AF can cause tricuspid regurgitation. ${ }^{4}$ However, I can argue that late tricuspid regurgitation can cause $\mathrm{AF}$, at least in some

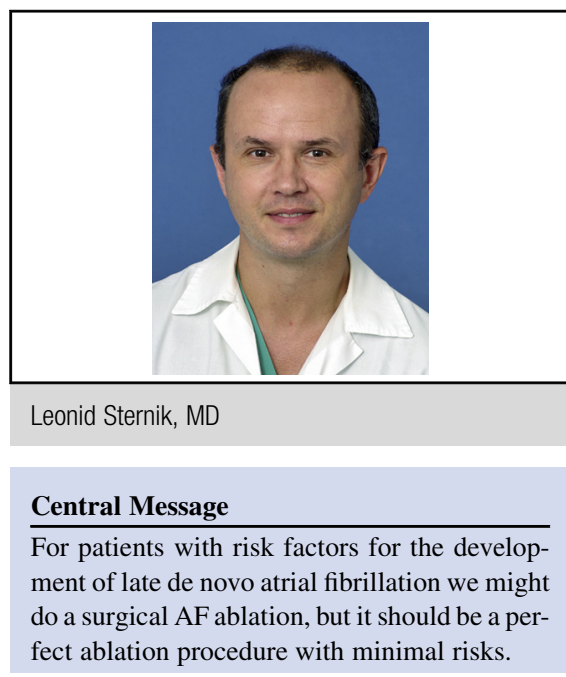

See Article page 1515 .

cases. It seems to me, that to prevent late de novo AF we should treat carefully in-hospital AF after cardiac surgery and pay attention to the tricuspid valve while performing surgery. It can be easier to put an annuloplasty ring than to treat late de novo $\mathrm{AF}$ with severe tricuspid regurgitation.

Now we are entering the era of very safe cardiac surgical procedures. No one is surprised anymore with $0.1 \%$ surgical mortality of mitral repair. The additional use of a surgical AF ablation procedure should add no mortality and morbidity. ${ }^{5}$ So, for patients with risk factors for the development of late de novo AF we might do a surgical AF ablation, but it should be a perfect ablation procedure with minimal risks.

\section{References}

1. Mehta CK, McCarthy PM, Andrei A-C, Kruse J, Shi H, Churyla A, et al. De novo atrial fibrillation after mitral valve surgery. J Thorac Cardiovasc Surg. 2018;1515-25.e11.

2. Stulak JM, Suri RM, Dearani JA, Sundt TM III, Schaff HV. When should prophylactic maze procedure be considered in patients undergoing mitral valve surgery? Ann Thorac Surg. 2010;89:1395-401.

3. Ad N, Henry L, Hunt S, Stone L. The implementation of a comprehensive clinical protocol improves long-term success after surgical treatment of atrial fibrillation. J Thorac Cardiovasc Surg. 2010;139:1146-52.

4. Stulak JM, Schaff HV, Dearani JA, Orszulak TA, Daly RC, Sundt TM III. Restoration of sinus rhythm by the Maze procedure halts progression of tricuspid regurgitation after mitral surgery. Ann Thorac Surg. 2008;86:40-4; discussion: 44-5.

5. Ad N, Henry L, Massimiano P, Pritchard G, Holmes SD. The state of surgical ablation for atrial fibrillation in patients with mitral valve disease. Curr Opin Cardiol. 2013;28:170-80. 